\title{
Classification and identification thresholds for three types of verbal materials'
}

\author{
WILMA A. WINNICK, QUEENS COLLEGE OF THE CITY UNIVERSITY OF NEW YORK \\ RHEA L. DORNBUSH, DOUGLASS COLLEGE, RUTGERS, THE STATE UNIVERSITY
}

The first two experiments found thresholds for classification into one of three categories of English words, Turkish words, and letter alternations to be significantly lower than thresholds for the identification of the specific items; parallel results were found with the two methods of measurement employed. Both thresholds were lowest for English words, and classification thresholds were lower for Turkish words than for letter alternations, but the identification thresholds of these two kinds of materials showed a reversal. The third experiment found classification thresholds for the same three types of materials to be higher than either of two three-choice identification thresholds, one a choice among three sametype items and the other, a choice among one English word, one Turkish word, and one letter alternation.

The possibility that thresholds for the classification of materials may differ from thresholds for exact identification has been suggested by findings in three related areas of study.

First, several experimental studies that have followed the subliminal perception experiments have come up with the suggestion that (in the words of Bricker \& Chapanis, 1953): "Even when an S's first verbal response to a stimulus is wrong, the stimulus may still have conveyed useful information to him" (p. 185). The findings from the Bricker and Chapanis (1953) study specifically suggested that, prior to exact identification, there may be cues that enable $\mathrm{S}$ to place the exposed material as belonging to a class or group of stimuli. Similar suggestions have been made by Boardman (1957), Osgood (1957) and Eriksen (1958).

Secondly, a number of recent studies have been concerned with the effects of repeated sub-threshold exposures on obtained identification thresholds. Boardman (1957) suggested that fragmentary cues available at durations below threshold may contribute to the final identification of the word. Both Harcum (1964) and Haslerud (1964) have reported facilitative effects of prerecognition exposures on identification. Most recently, Haber and Hershenson (1965) reported that, with duration constant, the probability of perceiving a word increased with the number of exposure trials. These authors conclude: ". . . it appears that information received and processed on one flash facilitates perception of a word on the next flash..." (p. 45). That the information received in this manner may relate to the classification of these words into categories is explored in the present study.

Further background is provided by a number of studies of right-left differences in ease of tachistoscopic recognition of different materials (e.g., Dornbush \& Winnick, 1965; Heron, 1957; Terrace, 1959; Winnick \& Dornbush, 1965). These studies have shown that the extent of right-field superiority depends upon the nature of the materials seen, as well as the manner of presentation. The two studies by the present authors (Dornbush \& Winnick, 1965; Winnick \& Dornbush, 1965) yielded evidence indicating that different kinds of verbal materials (English words, anagrams and paralogs varying in order of approximation to English) a rouse different kinds of eye movements in the post-exposure interval. The evidence pointing to this possibility was the finding of greater right-field superiority for words than for letters or anagrams and increases in right-field superiority as paralogs more closely approximated English letter arrangements. If the formulation is correct, it requires that the kind of material be apprehended prior to exact identification.

The three experiments to be reported here have tested for the possibility that a classification of materials into some kind of categories may occur at an earlier stage than does exact identification. To allow for this possibility, the materials employed for these threshold measurements were materials having structural differences that should permit easy classification. Specifically, the materials used were English words, Turkish words, and letter alternations, all randomly presented. Previous studies have measured classification and identification thresholds for English words differing either in affectivity (Eriksen, Azuma, \& Hicks, 1959) or in meaning (Fuhrer \& Eriksen, 1960; Moray, 1961). That none of these studies found any reliable differences between thresholds for classification (e.g., as "emotional" or "nonemotional," as "color" or "animal" words) and those for identification does not preclude the possibility that structural characteristics of verbal materials may result in classification at durations lower than those needed for exact identification. Indicating that this may occur is a finding by Postman and Rosenzweig (1956). In $\mathrm{Ss}^{\prime}$ incorrect attempts to identify either English words or nonsense words, they found a high percentage of incorrect English words when English words were in fact exposed and a high percentage of nonsense words as errors when nonsense words were exposed. They conclude: "The discrimination of stimulus-elements appears to enable $\mathrm{S}$ to identify the items as being either English or nonsense even before he is able to respond correctly" (Postman \& Rosenzweig, 1956, p. 221). 


\section{EXPERIMENTS I ANO II}

The first two experiments compared, in the same Ss, classification and identification thresholds for three kinds of verbal materials: English words, Turkish words, and letter alternations, all presented in random order. The two experiments differed in the methods used to measure thresholds. Experiment I used an ascending method of limits for individual items; that is, an item was presented at .01 sec. and at increasingly longer durations by .005 sec. steps until correctly identified (Limits Method)。In Experiment II, all words were presented in random order at successive exposure durations, starting at .01 sec. and at increasingdurations by $.005 \mathrm{sec}$. steps (Random Series Method).

\section{Method}

Apparatus and materials. In both experiments, the materials used were 15 English words, 15 Turkish words, and 15 letter alternations. From these, three different lists, each consisting of five items of each type of material, were composed to be used in three replications. The materials used in the three replications were counterbalanced for initial letters in each category. Thus, the five Turkish words used in Group I (civadra, lokanta, enanwal, biwojni, saracik) were matched to the English ,words in Group II (citadel, location, enigma, bivouac, and satisfy) and to the letter alternations in Group III (cicicic, lololol, enenene, bibibib, sasasas); the Turkish words used in Group II (dilikli, iktitaf, kadirga, adafnaw, mecburi) were matched to the English words in Group III (dignify, ignoble, kindred, adequate, mercury) and to the letter alternations of Group I (dididid, igigigi, kikikik, adadada, mememem). Finally, the Turkish words used in Group III (nijaron, jandara, tavhane, udibnow, olmadik) were matched to the English words of Group I (nitrate, javelin, tangent, utility, olympic) and to the letter alternations in Group II (nininin, jajajaj, tatatat, utututu, olololo).

The materials were typewritten in capital letters with an IBM electric typewriter; letters were spaced one typewriter space apart, and each item was centered on the tachistoscope card for exposure in a Gerbrands tachistoscope.

Procedure. All Ss were given general instructions and preliminary training with the tachistoscope before the start of the experiment. They were then given the response sheets and told that after each exposure they were to give any or all of the following information: (1) classifications, by checking one of the columns labeled "English Word," "Foreign Word," "Letter Alternation"; (2) as many specific letters as they could see, in the appropriate column. In Experiment I (Limits Method), one sheet was used for each word; thus, S had available all of his previous responses to each word. In Experiment II (Random Series Method), one sheet was used for each exposure duration.

Subjects. The Ss were introductory psychology students from the Summer Session at Queens College, all
Table 1. Mean thresholds in milliseconds for classification and identification of the three types of materials in the two experiments.

\begin{tabular}{|c|c|c|c|}
\hline & & Classification & Identification \\
\hline \multirow{2}{*}{ English words } & Exp. 1 & 29.7 & 41.0 \\
\hline & Exp. II & 23.6 & 29.3 \\
\hline \multirow[t]{2}{*}{ Turkish words } & Exp. 1 & 54.1 & 114.6 \\
\hline & Exp. II & 34.0 & 120.4 \\
\hline \multirow[t]{2}{*}{ Letter alternations } & Exp. I & 65.8 & 90.2 \\
\hline & Exp. II & 40.8 & 80.0 \\
\hline
\end{tabular}

serving in the experiments as part of the course requirement; there were 15 Ss in each experiment.

\section{Results}

The two kinds of thresholds obtained in the two experiments are shown in Table 1, where it can be seen that, although parallel results were obtained, Experiment I had consistently higher thresholds than did Experiment II. In both experiments, identification thresholds were higher than were classification thresholds for the three kinds of materials, and differences in both types of thresholds are apparent for the three kinds of materials.

Two separate analyses of variance were carried out for the data of the two experiments, evaluating one "between-Ss" effect (replications) and two "within-Ss" effects (type of threshold, materials). These analyses found type of threshold to be highly significant in both experiments $(F=53.8$ in Experiment $I$ and 138.1 in Experiment II; $\mathrm{df}=1 / 12, \mathrm{p}<.005$ for both), as was materials ( $F=16.9$ in Experiment I and 54.4 in Experiment II; $\mathrm{df}=2 / 24, \mathrm{p}<.005$ for both). Of considerable interest is the significant interaction between type of threshold and materials $(F=16.2$ in Experiment $I$ and 74.9 in Experiment II; $\mathrm{df}=2 / 24, \mathrm{p}<.005$ for both). This significant interaction reflects the fact that correct classification of letter alternations had a higher mean threshold than did classification of Turkish words, while identification of letter alternations had a lower mean threshold than did identification of Turkish words. Obviously, classifying material as a letter alternation is much more helpful to subsequent identification than is classification as a foreign word. Most helpful, judged in terms of the size of the gap in thresholds, is classification as an English word.

\section{Discussion}

The finding that the thresholds from Experiment I (Limits Method) are higher than those from Experiment II (Random Series Method) only adds to the unclear results of previous comparisons of these two methods. One might predict from the results of Haber and Hershenson (1965) that the repeated exposures of the same words in Experiment I should result in lower thresholds than the method of randomizing words for successive exposure durations, as in Experiment II. On the other hand, the presence of incorrect classification or iden- 
tification responses on the response sheets used in Experiment I may hinder changes of responses to correct ones. This explanation is the one applied by Wyatt and Campbell (1951) to their finding of higher thresholds for the repeated presentation method than for random presentation. By contrast with these findings, Pierce (1963) found no difference in the two methods of threshold measurement, and Postman and Adis-Castro (1957) found the method of limits to yield lower duration thresholds. It seems quite likely that other methodological variations from study to study may interact with the effect of measurement method.

Differences in thresholds obtained as a function of type of materials are not explicable solely in terms of the amount of information involved for the three different kinds of material. English words, found to have lowest thresholds of all, actually contain more information than do the letter alternations; there are 210 possible vowelconsonant or consonant-vowel alternations, but many more seven- and eight-letter English words, and of course the number of "foreign" words is by definition infinite. That the classification and identification processes proceeded more rapidly for English words than for the letter alternations or the Turkish words is probably because, to use Bruner's (1957) term, the "models" for the English words are well developed and frequently used, while it is unlikely that any models exist for the other kinds of materials. Or, to use Lawrence's (1963) concept, English words may be viewed as having undergone a "coding" process, while letter alterations and Turkish words have not.

\section{EXPERIMENT III}

This experiment was designed to counteract two criticisms that might easily, and justifiably, be leveled at the first two experiments. The first is that measuring classification and identification thresholds in the same Ss may by its very nature force the latter to be higher than the former; that is, once an item is identified, it must of necessity also be classified. A second criticism could point out that the differences in classification thresholds and identification thresholds might be due to merely the difference in information content of the responses; that is, correct classification is based on one out of only three possible inputs, while identification is based on many more possible inputs.

Experiment III measured classification and identification thresholds in two separate groups by a method providing similar information content for identification as obtained for classification responses. This was accomplished by converting the identification situation into two three-choice situations. The classification situation, of course, is by its very nature a three-choice situation.

\section{Method}

Apparatus and materials. The three combinations of English words, Turkish words and letter alternations used in Experiments I and II were again employed in
Table 2. Mean thresholds in milliseconds for the three types of materials in the three groups of Experiment III

\begin{tabular}{lccc} 
Groups & $\begin{array}{l}\text { English } \\
\text { Words }\end{array}$ & $\begin{array}{l}\text { Turkish } \\
\text { Words }\end{array}$ & $\begin{array}{l}\text { Letter } \\
\text { Alternations }\end{array}$ \\
A: Classification & 29.3 & 39.3 & 47.4 \\
B: Homogeneous ident. & 19.3 & 20.0 & 19.0 \\
C: Heterogeneous ident. & 21.7 & 25.3 & 27.5 \\
\hline
\end{tabular}

three replications.

Procedure. Thresholds for the three types of words were measured by the method of Random Series in three groups, Group A was the classification group, and the procedure and instructions for this group were identical with those used in Experiment II, except that Ss were not required to identify the items and classification choice was indicated by a spoken response. In Groups $\mathrm{B}$ and $\mathrm{C}$, identification thresholds were measured by a multiple-choice method. After familiarization procedure, Ss were instructed that they would see an item in the tachistoscope and would be required to identify the item as one of three shown on a card immediately after exposure. In Group B (homogeneous choice), $\mathrm{S}$ was to identify each item by a choice from one of three sametype items (i.e., three English words, such as citadel, ignoble, utility). Ss in Group $\mathrm{C}$ (heterogeneous choice) based their identification on a choice from three different-type items (i.e., one English word, one Turkish word, one letter alternation, such as citadel, cicicic, civadra).

Subjects. The Ss were 45 introductory psychology students; there were 15 in each of three groups.

\section{Results}

Shown in Table 2 are the thresholds for the three groups for the three kinds of materials. From these data, it is obvious that the three-choice identification does not produce a threshold value equivalent to classification into one of three categories. Rather, the classification thresholds are much higher than either of the threechoice identification thresholds. The analysis of variance corroborated this statement by the finding of significance in the main effect of threshold type: $F=$ $20.05 ; \mathrm{df}=2 / 36, \mathrm{p}<.01$. Also significant were type of material and the threshold by type of material interaction: $F=13.28$, $\mathrm{df}=2 / 72$; and $F=6.25$, $\mathrm{df}=4 / 72$, respectively; $p<.01$ for both.

\section{Discussion}

The outstanding result of Experiment III is that reducing identification to a choice of one of three possibilities did not make these thresholds equivalent to the three-choice classification thresholds. From these results it is apparent that something more is involved in the process of classification than merely a choice of one of three equally likely alternatives. The homogeneous choice situation has shown the lowest thresholds. This is reasonable since, with the words used, 
correct choice could be achieved by identification of the initial letter only. In the heterogeneous choice situation, where all items had the same initial letters, the correct choice involved examination of larger portions of the item, hence the slightly higher thresholds. Finally, the classification into one of three categories required even closer scrutiny for more information-possibly about the letter positions or general structure of the materials. Thus, the three kinds of choices provided in the three groups seem to have made increasing perceptual demands upon $\mathrm{S}$.

\section{GENERAL DISCUSSION}

The data collected in these experiments fit a view of tachistoscopic recognition developed by Bmuner (1957). He points out the categorical nature of perceptual representation: "An input is allocated to a class of objects and achieves its identity thereby" (p.343). More specific identification is described as proceeding by a series of "successive approximations." Tuus, with the word "citadel" exposed, S may begin by recognizing fairly early that this has a letter arrangement suggesting classification as an English word; he may nextget cues that enable him to describe itas "not familiar" (i.e., of low frequency); there may follow a series of guesses cued by recognition of letters or letter patterns and some notions of similar words (e.g., "civilized", "citizen"), finally terminating in the correct choice. That these guesses do not necessarily appear in S's overt responses may be due to the lack of good "fit" of the guess to the other perceptual characteristics of the stimulus.

With this approach, the response alternatives provided may be viewed as determining the course and the cut-off point of this approximation procedure. Given three general categories as the response input, S's examination of the stimulus apparently involves a search for guidelines to decide this choice. This is a more difficult perceptual task than deciding which of three English words or which of three different-type items had been presented. For the homogeneous choice, helpful information is provided by the response input-that the word is an English word-and the perceptual task is made easy by a choice among three English words with different initial letters. Although the heterogeneous choice does not specify the kind of material, it requires a choice among three exemplars of the categories rather than the categories as such. This requirement presumably instigates an examination procedure different from that required for a broader categorization and results in lower thresholds, apparently because of the lesser amount of perceptual information required.

To conclude, this study has found that equating information content of the responses involved-which results in equal response limitation-does not produce equal ease of identification. Rather, correct decisions in the three situations required different kinds of perceptual information, and hence different threshold levels resulted.

\section{References}

Boardman, W. K. Utilization of word structure in prerecognition responses. J. Pers., 1957, 25, 672-685.

Bricker, P. D., \& Chapanis, A. Do incorrectly perceived tachistoscopic stimuli convey some information? Psychol. Rev., 1953, 60, 181-189.

Bruner, J. S. Neural mechanisms in perception. Psychol. Rev., $1957,64,340-358$.

Dombush, R. L., \& Winnick, W. A. Right-left differences in tachistoscopic identification of paralogs as a function of order of approximation to English letter sequences. Percept. mot. Skills, $1965,20,1222-1224$.

Eriksen, C. W. Subception: fact or artifact? Psychol. Rev., 1956, $63,74-80$.

Eriksen, C. W., Azuma, H., \& Hicks, R. Verbal discrimination of pleasant and unpleasant stimuli prior to specific identification. J. abnorm. soc. Psychol., 1959, 59, 114-119.

Fuhrer, M. J., \& Eriksen, C. W. The unconscious perception of the meaning of verbal stimuli. J. abnorm. soc. Psychol., 1960, 61, $432-439$.

Haber, R. N., \& Hershenson, M. The effects of repeated brief exposures on the growth of a percept. J. exp. Psychol., 1965, $69,40-46$.

Harcum, E. R. Effect of pre-recognition exposures on tachistoscopic word perception. Percept. mot. Skills, 1964, 19, 855-860.

Haslerud, G. M. Perception of words as a function of delays between summations of subliminal exposures. Percept. mot. Skills, 1964, 19, 130 .

Heron, W. Perception as a function of retinal locus and attention. Amer. J. Psychol, , 1957, 70, 38-48.

Lawrence, D. H. The nature of stimuli: some relationships between learning and perception. In S. Koch (Ed.), Psychology: $A$ study of a science. New York: McGraw-Hill, Vol. 5, 1963. Pp. 179-212.

Moray, N. Perceptual defence and filter theory. Nature, 1961, p. 940 .

Osgood, C. E. Motivational dynamics of language behavior. In M. R. Jones (Ed.), Nebraska Symposium on Motivation. Lincoln: University of Nebraska Press, 1957.

Pierce, J. Some sources of artifact in studies of tachistoscopic perception of words. J. exp. Psychol., 1963, 66, 363-370.

Postman, L., \& Adis-Castro, G. Psychophysical methods in the study of word recognition. Science, 1957, 125, 193-194.

Postman, L., \& Rosenzweig, M. R. Practice and transfer in the visual and auditory recognition of verbal stimuli. Amer. $J$. Psychol., 1956, 69, 209-226.

Terrace, H. S. The effects of retinal locus and attention on the perception of words. J. exp. Psychol., 1959, 58, 382-385.

Winnick, W. A., \& Dombush, R. L. Pre- and post-exposure processes in tachistoscopic identification. Percept. mot. Skills, $1965,20,107-113$.

Wyatt, D. F., \& Campbell, D. T. On the liability of stereotype of hypothesis. J. abnorm. soc. Psychol., 1951, 46, 496-500.

Note

1. Supported by grants from the National Institute of Health (No. 11580-01) and from the Graduate Division of the City University of New York. This paper was presented at the Eastern Psychological Association meetings in New York City, April 15, 1966.

(Received in the Editorial Office May 2, 1966.$)$ 